\title{
BMJ Open Last Year of Life Study Cologne (LYOL-C): protocol for a cross-sectional mixed methods study to examine care trajectories and transitions in the last year of life until death
}

Julia Strupp, ${ }^{1}$ Gloria Hanke, ${ }^{1}$ Nicolas Schippel, ${ }^{2}$ Holger Pfaff, ${ }^{3,4}$ Ute Karbach,,${ }^{3,4}$ Christian Rietz, ${ }^{2}$ Raymond Voltz, ${ }^{1,3,5,6}$ on behalf of CoRe-Net

To cite: Strupp J, Hanke G, Schippel N, et al. Last Year of Life Study Cologne (LYOL-C): protocol for a cross-sectional mixed methods study to examine care trajectories and transitions in the last year of life until death. BMJ Open 2018;8:e021211. doi:10.1136/ bmjopen-2017-021211

- Prepublication history for this paper is available online. To view these files, please visit the journal online (http://dx.doi. org/10.1136/bmjopen-2017021211).

JS and GH contributed equally.

Received 15 December 2017

Revised 19 March 2018

Accepted 21 March 2018

Check for updates

For numbered affiliations see end of article.

Correspondence to

Dr Julia Strupp;

julia.strupp@uk-koeln.de

\section{ABSTRACT}

Introduction The last year of life constitutes a particularly vulnerable phase for patients, involving nearly all health and social care structures. Yet, little scientific evidence is available that provides insight into the trajectories including the number and types of care setting transitions, transitions into palliative care and the dying phase. Only few studies have focused on difficulties associated with having to move between health and social care settings in the last year of life, although patients face a significant risk of adverse events. The Last Year of Life Study Cologne (LYOL-C) aims to fill this gap.

Methods and analysis LYOL-C is a mixed-methods study composed of four steps: (1) Claims data collected by the statutory health insurance funds of deceased persons will be analysed with regard to patient care trajectories, health service transitions and costs in the last year of life. (2) Patient trajectories and transitions in healthcare will additionally be reconstructed by analysing the retrospective accounts of bereaved relatives $(n=400)$ using a culturally adapted version of the Views of Informal Carers-Evaluation of Services Short Form questionnaire and the Patient Assessment of Care for Chronic Conditions Short Form questionnaire adapted for relatives. (3) Qualitative interviews with bereaved relatives $(n=40-60)$ will provide in-depth insight into reasons for transitions and effects on patients' quality of life. (4) Focus groups $(n=3-5)$ with Healthcare Professionals will be conducted to discuss challenges associated with transitions in the last year of life.

Ethics and dissemination Ethical approval has been obtained from the Ethics Commission of the Faculty of Medicine of Cologne University (\#17-188). Results will be submitted for publication in peer-reviewed journals and presented at national and international conferences. Trial registration number The study is registered in the German Clinical Trials Register (DRKS00011925) and in the Health Services Research Database (VfD_CoReNet_17_003806).

\section{BACKGROUND}

About $1 \%$ of the German population dies each year (eg, in the year 2015, 925200 deaths

\section{Strengths and limitations of the study}

- The Last Year of Life Study Cologne (LYOL-C) will be the first study in Germany to examine health and social care trajectories and transitions of patients in their last year of life until death (independent of patient age, underlying diagnoses or care settings) within an entire region that possesses optimal palliative and hospice care structures.

- Our survey sample will be recruited through multiple channels and with a comparatively large sample size $(n=400)$ for palliative settings to ensure variety in care trajectories and places of death.

- The mixed-methods design enables a multidimensional view to reconstruct the last year of life including the reports of bereaved relatives as well as healthcare professionals.

- Claims data can be validated externally with our survey data and vice versa while the interviews and focus groups enable a clarification of claims data and survey results with a multistakeholder perspective.

- The perspective of relatives cannot be seen as a direct substitute for a self-assessment of patients, although a moderate agreement between patient and proxy ratings develops over time.

out of a total population of 81.6 million). ${ }^{1}$ For each patient who passes away, there are approximately three to four relatives who go through a subsequent bereavement period. This means that $5 \%$ of our population is affected by death each year, with the relative and absolute numbers increasing with changes in demography. In the year 2013, $46 \%$ of patients in Germany died in hospitals, with mortality rates increasing with age: $55 \%$ dying in hospitals were aged 65 and above. In North-Rhine-Westphalia, $49 \%$ died in hospitals, yet most people prefer to die at home, and hospitals have been perceived as giving only little support to patients' needs at the 
end of life. Furthermore, home care is cost-effective when shifting the care of the dying patients from hospital to home. ${ }^{2-4}$ This is even more important as about one-third of the total health expenditure in a life span occurs during the last months of life, ${ }^{56}$ and there have been increases in both aggressive and non-aggressive care at the end of life with increasing multiple hospitalisations. ${ }^{7}$ Furthermore, recent studies report of worsening symptom prevalence in the last year of life and raise concerns about shortcomings in end-of-life care and that there remain persistent gaps in addressing symptoms near the end of life. ${ }^{89}$

The last year of life therefore constitutes a particularly vulnerable phase in life for patients, involving nearly all health and social care structures. Yet, so far, only very little scientific evidence is available that provides insight into the trajectories including the number and types of care setting transitions. Only few studies have focused on difficulties associated with having to move between health and social care settings in the last year of life, such as the burden to caregivers and cost of hospital transfers, ${ }^{10}{ }^{11}$ although patients face a significant risk of adverse events, for instance during the transition from hospital to home. ${ }^{12}$ The Last Year of Life Study Cologne (LYOL-C) aims to fill this gap by being the first study in Germany to examine patient trajectories (independent of age, underlying diagnoses or care settings) and transitions between care settings and experiences in the last year of life including palliative care integration and the dying phase within a specific region (Cologne). Trajectories are defined as “(...) a course of illness over time plus the actions taken by patients, families and health professionals to manage or shape the course". ${ }^{13}$ Gill et al ${ }^{14}$ have found that the illness leading to death does not predict a patient's trajectory. Therefore, it is necessary to identify typical trajectories in the last year of life and to thereby provide time frames and patterns of probable needs and support from health and social services for patients (and carers).$^{15}$ A transition "(...) occurs between two locations or settings of care, for example moving from hospital to a care home. It may also represent a shift in the nature of care, such as the decision not to continue with curative treatments". ${ }^{16}$ Regarding LYOL-C, we therefore concentrate (1) on transitions within the disease trajectory, that is, from a curative to a palliative approach as well as the dying phase and (2) transitions between healthcare structures, for example, hospital to home, nursing home to hospital. It is important to study the patients' and professionals' point of view on (1) which transitions take place, (2) what are the reasons and determinants for these transitions (eg, DRG-related factors), (3) what are the effects on patient quality of life, (4) whether how and when a palliative care approach was introduced and finally, (5) where and how patients die. Cologne, with its one million inhabitants, is representative of the German urban setting and already possesses optimal palliative and hospice care structures. ${ }^{17}$ The LYOL-C study is the first step in developing a stable regional End of Life Care Network, similar to the National End of Life Network in the $\mathrm{UK},{ }^{18}$ which will bring together all stakeholders caring for people at the end of life. This network will also serve as the basis for immediate and future patient-centred and value-based changes derived from the initial descriptive and hypothesis-generating data obtained within the Cologne Research and Development Network (CoRe-Net). LYOL-C, being one of the CoRe-Net subprojects, aims to improve the management of patients in their last year of life including the dying phase.

Patient preferences and values must be integrated more into the development of healthcare structures. ${ }^{19}$ This is especially relevant for and apparent in the last year of life, which is a major contributor to overall healthcare costs. ${ }^{5}$ Palliative care encompasses central elements associated with patient-centred and value-based care, including physical comfort and emotional support, dignity and respect during the dying process, shared decision-making, identifying and meeting the patient's needs and values and coordinating care. ${ }^{2021} \mathrm{~A}$ recent study showed that community-based specialist palliative care was associated with hospital cost reductions across multiple life-limiting conditions. ${ }^{22}$ Internationally it has been reported that despite the growing use of palliative and hospice care structures, there has been an increase in the number of transitions in the last year of life. ${ }^{1623}$ The primary contributors to this are structural factors (eg, financial, legal) and a lack of emphasis on increasing value for patients and relatives. ${ }^{24}$ The Patient-Centered Outcomes Research Institute has found that poorly executed transitions between healthcare settings can harm patients and lead to additional hospital visits ${ }^{25}$ which can be burdensome and decrease quality of life. ${ }^{23} 26$ In the USA, hospital readmission follows $12 \%-25 \%$ of hospital discharges in the last year of life, with almost $50 \%$ of readmissions going through an emergency room. ${ }^{27}$ The fact that caregivers are often emotionally and physically burdened with providing home care is one factor leading to admission into inpatient care settings, despite the fact that relatives' and patients' preferences for home care have not changed. A recent study has found that a greater understanding of family caregivers' preferences is needed to identify how best to support families at the end of life and to ensure more patients are cared for in a value-based way. ${ }^{28}$

For Germany, scientific evidence on the benefits of palliative care has emerged in recent years, currently mainly on specific aspects of care structures (eg, discharge after stay in a palliative care unit) ${ }^{29-31}$ or restricted to clinical questions, for example, pain or breathlessness. ${ }^{32-34} \mathrm{~A}$ general health services research approach incorporating all regional care structures is still missing. The city of Cologne, which is home to Germany's first palliative care unit founded at the University Hospital of Cologne in 1983, currently offers an area-wide palliative and hospice care setting including all care structures currently available by the German system. Cologne even has a three-level palliative care structure-general (general practitioners (GPs), nursing), intermediate (qualified palliative care 
physicians and palliative care nursing) and specialised palliative outpatient care-which is unique to the NorthRhine area. The city, therefore, provides the optimal urban setting for studying future health service developments in end-of-life care in Germany.

LYOL-C therefore aims to:

I. Examine care trajectories and transitions in the last year of life until death in Cologne.

II. Improve the management of patients in their last year of life including the dying phase by consented immediate action in a patient-centred and value-based way.

III. Derive further care innovations based on initial descriptive and hypothesis-generating data that could be evaluated in future studies.

The study period will be from February 2017 to January 2020.

\section{METHODS AND ANALYSIS}

LYOL-C is a mixed-methods study and consists of four phases:

\section{Phase I: Claims data analysis on the patient epidemiology of the last year of life}

Several statutory health insurance funds (SHI) will provide anonymised claims data, covering together $\sim 55 \%$ of the Cologne population. With regard to Cologne, about 800000 people are insured with the SHI. Taking into account that $1 \%$ of them die each year $(\sim 8.000),{ }^{35}$ we are able to analyse patient trajectories of all deceased insurees of the participating SHI funds. Counting backward from date of death, the last year of life can be assessed for those continuously insured until death using data from the respective SHI fund. In a first step, deceased patients are characterised according to age, sex, medication (eg, polypharmacy), morbidity (eg, Charlson and Elixhauser comorbidity measures assessed by International Classification of Diseases 10th Revision codes), use of long-term nursing care (level and place of care) and other health problems highly prevalent in patients at the end of life (eg, oral health issues). In addition, direct medical costs will be estimated for the last year of life according to sectors of care. Master data (eg, insurance time, pseudonymised unique patient identifier) will be used for defining the study population, while master data (sex, age, nursing care) and information from all sectors of care will be used for describing the population and analysing influencing factors on the outcome variables (eg, number of transitions, place of death) using multiple regression analysis. Trajectories between sectors of care can be analysed with the help of the pseudonymised patient identifiers. Emergency visits and hospital referrals according to doctor's specialty will be assessed. Analysis will be performed for all patients who died (excluding accidents and homicides). Analysis will provide a status quo of main care trajectories to be analysed in the following steps.

\section{Inclusion criteria}

Deceased person who lived in Cologne and died aged 18 years or older. We relate to deaths that have occurred in the last 12 months prior to the survey (November 2016 to April 2018).

\section{Phase II: Quantitative survey with bereaved informal caregivers to analyse patient trajectories in the last year of life}

Patient trajectories and transitions in healthcare will be reconstructed by analysing the retrospective accounts of bereaved relatives $(n=400)$. A questionnaire will be used, covering for example, the number and types of transitions between care settings, use of palliative care services and (best) timing of admission to palliative care services. Data will also be collected using the validated Views of Informal Carers-Evaluation of Services Short Form (VOICES-SF) questionnaire. VOICES is a postal questionnaire about experiences of end of life care in the last months of life, focusing on quality of care and services received. Using the postbereavement method, it gathers information from bereaved relatives, friends or carers acting as proxies. ${ }^{36}$ Within our study, we will adapt the questions of VOICES-SF to the German healthcare system and translate them into German. Procedures for translation and assessment are based on the team translation approach described by Harkness ('TRAPD'), ${ }^{37}$ which is also applied in cross-national social surveys (eg, European Social Survey, ${ }^{38}$ Programme for the International Assessment of Adult Competencies ${ }^{39}$ ). To analyse patient centredness, the Patient Assessment of Care for Chronic Conditions Short Form (PACIC-SF) ${ }^{40-42}$ will be applied. The PACIC-SF adapted for relatives will be validated in the course of our project. The instrument measures the extent to which patients receive care that is patient centred, proactive, planned and includes collaborative goal setting, problem solving and follow-up support. It is a validated patient self-report instrument and will be adapted for usage with bereaved relatives. Participants will be recruited mainly via our field access partners, for example, hospices, care facilities, nursing homes, specialised outpatient palliative care services, palliative care units, ecclesiastical institutions, community centres and funeral homes. Recruitment will also be done via newspaper advertisements, GPs, local GP networks (snowballing technique) and local bereavement groups run by palliative hospice structures. We expect recruitment to go smoothly, as recruitment also went rapidly in previous research projects, such as on multiple sclerosis. ${ }^{434}$

The survey design allows comparisons to be made between the quality of care given to people dying at different ages (for example less than 65 years, 65-79 years or 80 years or more) and different causes of death (cardiovascular, cancer or other) and for people receiving care in different settings during the last months of life (for example home, hospital, care home and/or hospice). Analysis is undertaken in various statistical packages using weights and the sampling stratification. The VOICES survey, for example, calculates a weight for each response 
to the survey, to account for biases within the sample design, adjust for non-response bias and calibrate weights to the population of the sampling frame. These weights are used to calculate weighted percentages. Data will be analysed using SPSS Statistics V.24.

\section{Inclusion criteria}

Relatives, friends, carers and volunteers can be included if (1) they are 18 years or older, (2) they have cared for a deceased person in his/her last year of life, (3) the deceased person was 18 years or older and (4) his/her death has occurred in the last 12 months.

\section{Exclusion criteria}

Accidental death and killing.

\section{Phase III: In-depth interviews with bereaved informal caregivers to gain insight into patient trajectories}

Qualitative interviews ( $\mathrm{n}=40$ to 60 , by means of purposeful sampling to secure maximum heterogeneity) with bereaved relatives will provide in-depth insight into the reasons for transitions and the effects on the quality of life of the patients, including in the dying phase. Relatives will be recruited based on the type of care trajectory, the five most frequent types of trajectories (as reconstructed from the claims data analysis and questionnaire survey), site of death, underlying diagnoses, living situation, age and sex of the deceased. Interviews will follow a topic guide to ensure consistency across interviews. Interviews will be conducted during the first 12 months after death to ensure that relatives' memories are sufficiently fresh for them to provide details about their experiences. They can decide by themselves about the best timing for them to participate in the interview and feel able to speak about their experiences without becoming too upset. All interviews will be recorded, transcribed verbatim and anonymised.

Krueger and Casey ${ }^{45}$ advocate the use of a computer-based approach for cutting, pasting, sorting, arranging and rearranging data through comparing and contrasting the relevant information. For this purpose we will use MAXQDA, a professional software for qualitative data analysis, as already mentioned for analysing patient trajectories via qualitative interviews. Data will be analysed according to Fisseni ${ }^{46}$ and applying qualitative content analysis according to Flick ${ }^{47}$ which has already been successfully performed in some of our own studies. ${ }^{48} 49$

\section{Inclusion criteria}

See phase II.

\section{Exclusion criteria}

See phase II.

\section{Phase IV: Focus groups with healthcare professionals to analyse views on transitions}

Focus groups $(\mathrm{n}=3-5)$ with healthcare professionals (HCPs) will be conducted to discuss challenges associated with transitions in the last year of life and identify key issues and possibilities for improvements in the organisation. Following analysis of the data extracted in phases I to III, focus groups will be conducted with key health and social care providers involved in the care of people in the last year of life within hospital and outpatient settings, nursing homes, hospices and so on. The aim is to explore current practice in health and social care management and the way that transitions to a palliative care approach and transitions between structures are managed in different settings and how the care organisations are able to assess patient needs and preferences. This phase will be conducted with support from our field access partners. Purposive sampling will be used to select a diverse range of HCPs and achieve the maximum possible variation of experience and opinion. Data will be analysed according to Fisseni ${ }^{46}$ and applying qualitative content analysis according to Flick. ${ }^{47}$

\section{Inclusion criteria}

HCPs involved in the care of people in the last year of life in Cologne.

\section{Patient and public involvement}

Patient and public involvement (PPI) has been embedded in the study from conception, one PPI contributor for instance was a cooperation partner and bereaved relative. We had support in the development of the research design from several collaboration partners to discuss the relevance of the study and that it will be participant friendly and ethically sound.

To enhance PPI even further, a meeting with field access partner was conducted to inform each phase of the study design. Furthermore, a network meeting took place with more than 70 participants. This meeting intended to inform about CoRe-Net and create the future of the Cologne Research and Development Network together. The meeting was attended by patient and relative representatives, representatives from health insurances and the medical chamber, science and medical professions, besides many others involved in health and social care in Cologne. Each meeting was constructed around various phases of the research project. The face-to-face meetings included presentations by the research team about the study and its progress.

With regard to disseminating results to study participants, the results and deliverables will be disseminated within the region of Cologne via the Cologne lab conferences and CoRe-Net-Public Relations. Through the networks and projects in which the members of CoRe-Net are key stakeholders, national and international dissemination of experience can be assured. For LYOL-C, dissemination will be done via, for example, the National Society for Palliative Care, the National Palliative Care Strategy, the European Association for Palliative Care, the European Academy of Palliative Care and the UK End-of-Life Network with our collaboration partner Prof Dr Sheila Payne. 


\section{ETHICS AND DISSEMINATION}

People who are approaching the end of life are particularly vulnerable. We will therefore analyse the views of bereaved relatives as well as health professionals and analyse claims data to describe patients' trajectories. The Oxford Textbook of Palliative Medicine ${ }^{50}$ sets out five ethical aspects that should be considered when undertaking palliative care research: the study's potential benefits to future patients, the study's potential benefits to subjects, the study's risk to subjects, subjects' decision-making capacity and the voluntariness of subjects' choices about research participation. All these aspects will be addressed within our project and all respondents will only participate with an informed consent.

Restructuring complex care for vulnerable patients at the end of life is highly needed in Germany because these patients often are lost in transition between multiprofessional and multi-institutional care providers. This generates unnecessary costs, ill health and thus low value for patient and their relatives and caregivers. The results of our study will be disseminated within the region of Cologne via the Cologne lab conferences and CoRe-Net public relations. To further implement regional changes, CoRe-Net will be immediately 'available' as a 'Cologne lab' with collaboration partners, a large database and standardised pathways derived from the projects. Possible changes that can be directly implemented after the first funding phase (years 1-3) of LYOL-C are, for example, 'round tables' for health professionals treating patients in their last year of life to discuss sign posts for transitions.

Results of all four phases will be submitted for publication in peer-reviewed journals and presented at national and international conferences.

\section{Author affiliations}

${ }^{1}$ Department of Palliative Medicine, Medical Faculty, University of Cologne, Cologne, Germany

${ }^{2}$ Faculty of Human Sciences, Working Area Research Methodology, University of Cologne, Cologne, Germany

${ }^{3}$ Center for Health Services Research Cologne (ZVFK), University of Cologne, Cologne, Germany

${ }^{4}$ Institute of Medical Sociology, Health Services Research, and Rehabilitation Science (IMVR), University of Cologne, Cologne, Germany

${ }^{5}$ Center for Integrated Oncology Cologne/Bonn (CIO), University of Cologne, Cologne, Germany

${ }^{6}$ Clinical Trials Center Cologne (ZKS), University of Cologne, Cologne, Germany

Acknowledgements The authors would like to thank the BMBF for funding this study (\#01GY1606) as well as our field access partner for their support. We would also like to acknowledge the support from our CoRe-Net Co-applicants. We would also like to thank Dieter Jänsch for his support as a patient adviser and relative for his enormous support.

Collaborators The CoRe-Net Co-applicants: Professor Dr Christian Albus, Department of Psychosomatics and Psychotherapy, Faculty of Medicine (FM), University Hospital Cologne (UHC), Jun-Professor Dr Lena Ansmann, Institute of Medical Sociology, Health Services Research and Rehabilitation Science (IMVR), Faculty of Human Sciences (FHS), University of Cologne (UoC), Professor Dr Frank Jessen, Department of Psychiatry and Psychotherapy, FM, UHC, Professor Dr Ludwig Kuntz, Department of Business Administration and Health Care Management, Faculty of Management, Economics and Social Sciences (FMESS), UoC, Dr Ingrid Schubert, PMV Health Care Research Group, FM, UoC, Professor Dr Frank Schulz-Nieswandt, Institute for Sociology and Social Psychology, FMESS,
UoC, Professor Dr Stephanie Stock, Institute for Health Economics and Clinical Epidemiology, FM, UHC.

Contributors JS, CR and RV are principal investigators and responsible for the study design and project management. GH is responsible for the operative management of LYOL-C, recruitment, data collection, data analysis and dissemination. NS is responsible for the recruitment, data collection, data analysis and dissemination. HP and UK are principal investigators of CoRe-net and responsible for methodological consulting. All authors read an approved the final manuscript.

Funding This work was supported by the German Federal Ministry of Education and Research (BMBF), grant number \#01GY1606.

Competing interests None declared.

Patient consent Not required.

Ethics approval Ethical approval for this study was obtained from the Ethics Commission of the Faculty of Medicine of Cologne University (\#17-188).

Provenance and peer review Not commissioned; externally peer reviewed.

Data sharing statement The datasets generated and/or analysed during the current study are available from the corresponding author on reasonable request.

Open Access This is an Open Access article distributed in accordance with the Creative Commons Attribution Non Commercial (CC BY-NC 4.0) license, which permits others to distribute, remix, adapt, build upon this work non-commercially, and license their derivative works on different terms, provided the original work is properly cited and the use is non-commercial. See: http://creativecommons.org/ licenses/by-nc/4.0/

(C) Article author(s) (or their employer(s) unless otherwise stated in the text of the article) 2018. All rights reserved. No commercial use is permitted unless otherwise expressly granted.

\section{REFERENCES}

1. Bundesamt S. Gesundheit: Todesursachen in deutschland [causes of death in Germany]. Wiesbaden: Statistisches Bundesamt, 2015.

2. Pham B, Krahn M. End-of-life care interventions: an economic analysis. Ont Health Technol Assess Ser 2014;14:1-70.

3. Gomes B, Calanzani N, Higginson IJ. Benefits and costs of home palliative care compared with usual care for patients with advanced illness and their family caregivers. JAMA 2014;311:1060-1.

4. Smith S, Brick A, O'Hara S, et al. Evidence on the cost and costeffectiveness of palliative care: a literature review. Palliat Med 2014;28:130-50.

5. Hogan C, Lunney J, Gabel J, et al. Medicare beneficiaries' costs of care in the last year of life. Health Affairs 2001;20:188-95.

6. Lubitz JD, Riley GF. Trends in Medicare payments in the last year of life. N Engl J Med 1993;328:1092-6.

7. Riley GF, Lubitz JD. Long-term trends in medicare payments in the last year of life. Health Serv Res 2010;45:565-76.

8. Singer AE, Meeker D, Teno JM, et al. Symptom trends in the last year of life from 1998 to 2010: a cohort study. Ann Intern Med 2015;162:175-83.

9. Walling AM, Asch SM, Lorenz KA, et al. The quality of care provided to hospitalized patients at the end of life. Arch Intern Med 2010;170:1057-63.

10. Halasyamani L, Kripalani S, Coleman E, et al. Transition of care for hospitalized elderly. Hosp Med 2006;6:354-60.

11. Ma E, Coleman EA, Fish R, et al. Quantifying posthospital care transitions in older patients. J Am Med Dir Assoc 2004;5:71-4.

12. Forster AJ, Murff HJ, Peterson JF, et al. The incidence and severity of adverse events affecting patients after discharge from the hospital. Ann Intern Med 2003;138:161-7.

13. Corbin JM. The corbin and strauss chronic illness trajectory model: an update. Sch Inq Nurs Pract 1998;12:33-41.

14. Gill TM, Gahbauer EA, Han L, et al. Trajectories of disability in the last year of life. N Engl J Med 2010;362:1173-80.

15. Murray SA, Kendall M, Boyd K, et al. Illness trajectories and palliative care. BMJ: British Medical Journal 2005;330:1007-11.

16. Hanratty B, Lowson E, Grande G, et al. Transitions at the end of life for older adults - patient, carer and professional perspectives: a mixed-methods study. Health Services and Delivery Research 2014;2:1-102.

17. Erdogan-Griese B. Palliativmedizin im Rheinland: ein starkes Netz für das Leben [Palliative Care in the Rhineland: a strong net for life]. Rheinisches Ärzteblatt 2012:12-13. 
18. National End of Life Care Intelligence Network. What do we know now that we didn't know a year ago? New intelligence on end of life care in England, 2012.

19. Porter ME, Pabo EA, Lee TH. Redesigning primary care: a strategic vision to improve value by organizing around patients' needs. Health Aff 2013;32:516-25.

20. Singer PA, Martin DK, Kelner M. Quality end-of-life care: patients' perspectives. JAMA 1999;281:163-8.

21. Teno JM, Casey VA, Welch LC, et al. Patient-focused, familycentered end-of-life medical care. Journal of Pain and Symptom Management 2001;22:738-51.

22. Spilsbury K, Rosenwax L. Community-based specialist palliative care is associated with reduced hospital costs for people with non-cancer conditions during the last year of life. BMC Palliat Care 2017;16:68.

23. Gozalo P, Teno JM, Mitchell SL, et al. End-of-life transitions among nursing home residents with cognitive issues. $N$ Engl $\mathrm{J} \mathrm{Med}$ 2011;365:1212-21.

24. Weber M, Claus M, Zepf Kl, et al. Dying in Germany: unfulfilled needs of relatives in different care settings. J Pain Symptom Manage 2012;44:542-51.

25. Patient-Centered Outcomes Research Institute (pcori). In care transitions, a chance to make or break patients' recovery. Secondary In care transitions, a chance to make or break patients' recovery. 2015. http://www.pcori.org/research-in-action/care-transitionschance-makeor-break-patients-recovery

26. Smeenk F, de Witte LP, van Haastregt JCM, et al. Transmural care. Patient Education and Counseling 1998;35:189-99.

27. Coleman EA, Min SJ, Chomiak A, et al. Posthospital care transitions: patterns, complications, and risk identification. Health Serv Res 2004;39:1449-66.

28. Woodman C, Baillie J, Sivell S. The preferences and perspectives of family caregivers towards place of care for their relatives at the endof-life. A systematic review and thematic synthesis of the qualitative evidence. BMJ Support Palliat Care 2016;6:418-29.

29. Jors K, Adami S, Xander C, et al. Dying in cancer centers: do the circumstances allow for a dignified death? Cancer 2014;120:3254-60.

30. Kötzsch F, Stiel S, Heckel M, et al. Care trajectories and survival afte discharge from specialized inpatient palliative care-results from an observational follow-up study. Support Care Cancer 2015;23:627-34.

31. Pinzón LCE, Claus M, Zepf KI, et al. Symptom prevalence in the last days of life in Germany. American Journal of Hospice and Palliative Mediciner 2011;29:431-7.

32. Simon ST, Weingärtner V, Higginson IJ, et al. Definition, categorization, and terminology of episodic breathlessness: consensus by an international Delphi survey. J Pain Symptom Manage 2014;47:828-38.

33. Simon ST, Weingärtner V, Voltz R, et al. Episodic breathlessness: a clinically relevant and rising issue. Ann Am Thorac Soc 2014;11:274-74.

34. Weingaertner V, Scheve C, Gerdes V, et al. Breathlessness, functional status, distress, and palliative care needs over time in patients with advanced chronic obstructive pulmonary disease or lung cancer: a cohort study. J Pain Symptom Manage 2014;48:569-81.
35. Bundesamt S. Bevölkerung und Erwerbstätigkeit Zusammenfassende Übersichten - Eheschließungen, Geborene und Gestorbene: 1946 - 2015 [Population and Employment. Overview Marriages, Born and Died: 1946 - 2015]. Wiesbaden: Statistisches Bundesamt, 2016.

36. Hunt K, Addington-Hall JM. A toolkit for the design and planning of locally-led VOICES surveys. Secondary a toolkit for the design and planning of locally-led VOICES surveys 2011

37. Harkness J. Questionnaire translation. In: Harkness J, van de Vijver FJR, PPh M, eds. Cross-cultural survey methods. New York: Wiley, 2003:35-56.

38. European Social Survey. ESS round 8 translation guidelines. Secondary ESS round 8 translation guidelines. 2016. http://www. europeansocialsurvey.org/docs/round8/methods/ESS8_translation_ guidelines.pdf

39. Ferrari A, Wayrynen L, Behr D, et al. Translation, adaptation, and verifi cation of test and survey materials. Technical report of the survey of adult skills (PIAAC) Paris: chapter 4, 2013:1-28.

40. Gensichen J, Serras A, Paulitsch MA, et al. The patient assessment of chronic illness care questionnaire: evaluation in patients with mental disorders in primary care. Community Ment Health $\mathrm{J}$ 2011;47:447-53.

41. Goetz K, Freund T, Gensichen J, et al. Adaptation and psychometric properties of the PACIC short form. Am J Manag Care 2012;18:e55-e60.

42. Rosemann T, Laux G, Droesemeyer S, et al. Evaluation of a culturally adapted German version of the Patient Assessment of Chronic Illness Care (PACIC 5A) questionnaire in a sample of osteoarthritis patients. J Eval Clin Pract 2007;13:806-13.

43. Golla H, Galushko M, Pfaff $H$, et al. Multiple sclerosis and palliative care-perceptions of severely affected multiple sclerosis patients and their health professionals: a qualitative study. BMC Palliat Care 2014;13:11

44. Strupp J, Golla H, Galushko M, et al. Self-rating makes the difference: identifying palliative care needs of patients feeling severely affected by multiple sclerosis. Palliat Support Care 2015;13:733-40.

45. Krueger RA, Casey MA. Focus Groups. A Practical Guide for Applied Research. 3rd ed. Thousand Oaks, CA: Sage Publications, 2000.

46. Fisseni H. Persönlichkeitsbeurteilung. Zur Theorie und Praxis des psychologischen Gutachtens; eine Einführung [Personality assessment. An introduction to theory and practice of psychological reports]. Toronto, Zürich: Hogrefe, Verl. für Psychologie, 1992.

47. Flick U. Qualitative Sozialforschung. Eine Einführung [Qualitative research. An introduction]. Rowohlt: Reinbek bei Hamburg, 2007.

48. Rudinger G, Rietz C. Methodological issues in a cross-European study. Amsterdam: IOS, 1999.

49. Illes F, Rietz C, Rudinger G, et al. Der Genethik-Fragebogen. ein Instrument zur Erfassung der Einstellung zu psychiatrisch-genetischer Untersuchung und Forschung [the genethic questionnare. An instrument to measure attitudes toward psychiatric-geneticresearch] Bonn: PACE, 2003

50. Hanks G, Cherny N, Christakis N, et al. Oxford Textbook of Palliative Medicine. Oxford, UK: Oxford University Press, 2015. 